\title{
Variable speed turbine based wind farm including storage system connected to a power grid or islanded
}

\author{
A. Davigny and B. Robyns \\ Laboratoire d'Electrotechnique et d'Electronique de Puissance de Lille (L2EP) \\ Ecole des Hautes Etudes d'Ingénieur (HEI) \\ 13, rue de Toul, F - 59046 Lille Cedex (France) \\ Phone:+33 3283848 58, fax:+33 3283848 04, e-mail: arnaud.davigny@hei.fr, benoit.robyns@hei.fr
}

\begin{abstract}
In this paper, the possibility of a generating system, which associates a variable speed wind turbine and a flywheel energy storage system, to participate to the ancillary services is investigated. The connection to a power grid of a farm including three of them is considered. A solution is proposed to allow wind generators to work as voltage sources with the help of a frequency droop. It is shown that the power generated by these systems can be controlled by fixing the power set point when they are connected to the grid, and that, in case of islanding, they can share the global load of the isolated network
\end{abstract}

\section{Keywords}

Dispersed generation, wind farm, energy storage, power converter, ancillary services, islanding.

\section{Introduction}

The electricity market liberalization and the development of the decentralized production induce many new scientific and technical problems. The major problem experienced with decentralized energy sources, and particularly renewable energy ones, is that they do not usually contribute to the power network management [1]. Their rate of penetration is then limited (to $30 \%$ of the consumption for instance according to some experience feedback [1] [2]) in order to be able to guarantee the network stability under acceptable conditions. Among these sources, wind energy is expected to grow quickly in Europe during the coming years. Increasing its rate of penetration will be thus possible if this type of source takes part in the ancillary services [2] - [4], and can work in islanding mode.

To reach these objectives with wind generators, we consider a Variable Speed Wind Turbine (VSWT) coupled to a Permanent Magnet Synchronous Generator (PMSG) combined to an energy storage system [5]. Due to important fluctuations of the wind generator power, conventional electrochemical batteries are not adapted [4]. We consider then a Flywheel Energy Storage System (FESS) [6] [7]. Owing to the use of power electronics, the generator and the storage system are electrically coupled via a DC link.

To evaluate the possibility of the proposed generating system (GS) to participate to the ancillary services, we consider in this paper the connection of a wind farm including three generating systems with a network including passive loads and a power grid. Generating systems are working as voltage sources with the help of a frequency droop [8]. It is shown in this paper, with the help of simulations, that the power generated by each generating system can be controlled by fixing the power set point when they are connected to the grid. It is also shown in case of islanding, that they can share the global load of the isolated network like Uninterruptible Power Supply (UPS) parallel connection [9] - [11]. This paper focus particularly on the system behaviour working in islanding mode when load varies.

\section{Studied Generating System}

\section{A. Generating System structure}

Fig. 1. shows the generating system under study [5]. The pitch controlled wind turbine is directly coupled to a PMSG of 42 pole pairs. The flywheel is coupled to an induction machine of one pole pair. The rated power of the induction machine is $600 \mathrm{~kW}$. The inertia of the flywheel is determined in order to generate the induction machine rated power during two minutes with a speed range of $3000-6000 \mathrm{rpm}$. Working over the rated speed and then, in the field weakening region, allows to generate or store the rated power of the induction machine. To ensure a good voltage quality and to allow the feeding of isolated loads, a LC filter is included between converter 3 and the network as shown in Fig. 1. The inductance $L_{2}$ in Fig. 1 may represent a transformer one.

\section{B. Generating System proposed control}

\section{1) General principles}

In Fig. 1, Converter 1 allows to extract the maximum power from the wind. If necessary, the power generation can be controlled in order to be lower than the maximum, leading to a speed limitation by pitching the blades. In this particular case study, the maximum power value of the generating system is fixed to $600 \mathrm{~kW}$. The DC link voltage $\mathrm{U}_{\mathrm{DC}}$ can be controlled by one of the three power converters. In classical VSWT this voltage is usually regulated by converter 3 . Owing to the storage system 


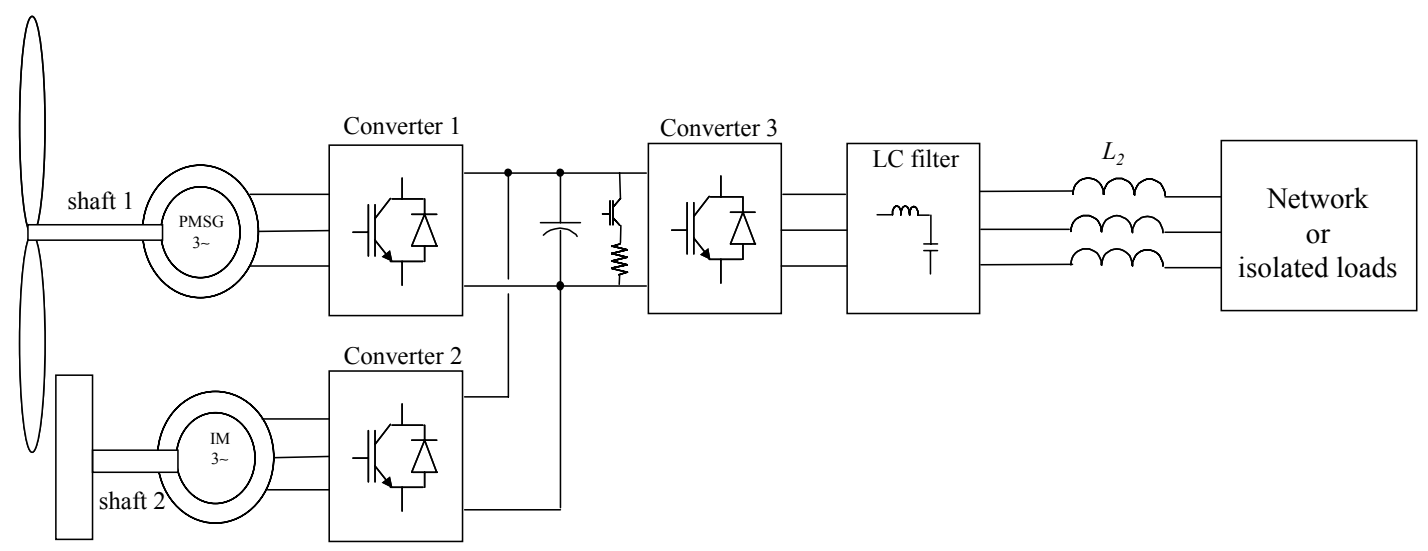

Fig. 1. Scheme of a generating system.

connected to converter 2 , converter 3 can then focus on the network voltages and frequency control. Converter 2 then controls $\mathrm{U}_{\mathrm{DC}}$ by storing or producing power to ensure the generation/consumption balance.

As the FESS cannot store or generate indefinitely, it is proposed to decrease the power generation of the VSWT in case of high flywheel speed (5500 rpm) and to change the level of the active power supplied by converter 3 in case of low flywheel speed $(3500 \mathrm{rpm})$. Fig. 2 (subscripts "meas" and "ref" refer respectively to measured and reference values) shows the control scheme of converter 3 which therefore directly controls the phase - to - phase capacitor voltages $u_{c}$ of the LC filter with the help of resonant controllers [5], allowing the generating system to work as an ideal voltage source. Transfer function of these controllers is the following :

$$
C_{u i}(s)=\frac{r_{u i 0}+r_{u i 1} s+r_{u i 2} s^{2}+r_{u i 3} s^{3}}{\left(\omega_{0}^{2}+s^{2}\right)\left(\sigma_{u i 0}+\sigma_{u i 1} s\right)}
$$

In this equation, $\omega_{0}$ is the pulsation associated with the network frequency $f_{0}, r_{\text {ui } 0}$ to $r_{\text {ui3 }}$ and $\sigma_{\text {ui0 }}, \sigma_{\text {ui } 1}$ are coefficients. $s$ is the Laplace operator. In Fig. $2, i_{\mathrm{g} 1}$ and $i_{\mathrm{g} 2}$ are the generating system phase 1 and 2 currents.

\section{2) Voltage and frequency control}

The frequency of the voltage reference wave is determined with the help of frequency droop allowing a load sharing when generating systems are interconnected. The phase - to - phase capacitor voltage reference waves are determined as follows :

$$
\begin{aligned}
& u_{c 13 r e f}=U_{r e f} \sqrt{2} \sin \left(2 \pi f_{0} t-\frac{\pi}{6}+\delta\right) \\
& \mathrm{u}_{\mathrm{c} 23 \mathrm{ref}}=\mathrm{U}_{\mathrm{ref}} \sqrt{2} \sin \left(2 \pi \mathrm{f}_{0} \mathrm{t}-\frac{\pi}{2}+\delta\right)
\end{aligned}
$$

$f_{0}$ is the rated frequency. $U_{\text {ref }}$ is the rms reference voltage. $\delta$ is the phase difference between the LC filter capacitor voltages and the network ones. In case of islanding, $U_{\text {ref }}$ is determined in order to compensate for $\mathrm{L}_{2}$ voltage drop which depends on the reactive power $\mathrm{Q}_{\mathrm{g}}$. The angle $\delta$ allows to control the active power $\mathrm{P}_{\mathrm{g}}$ generated by the generating system onto the network as shown by (3) deduced from Fig. 3.

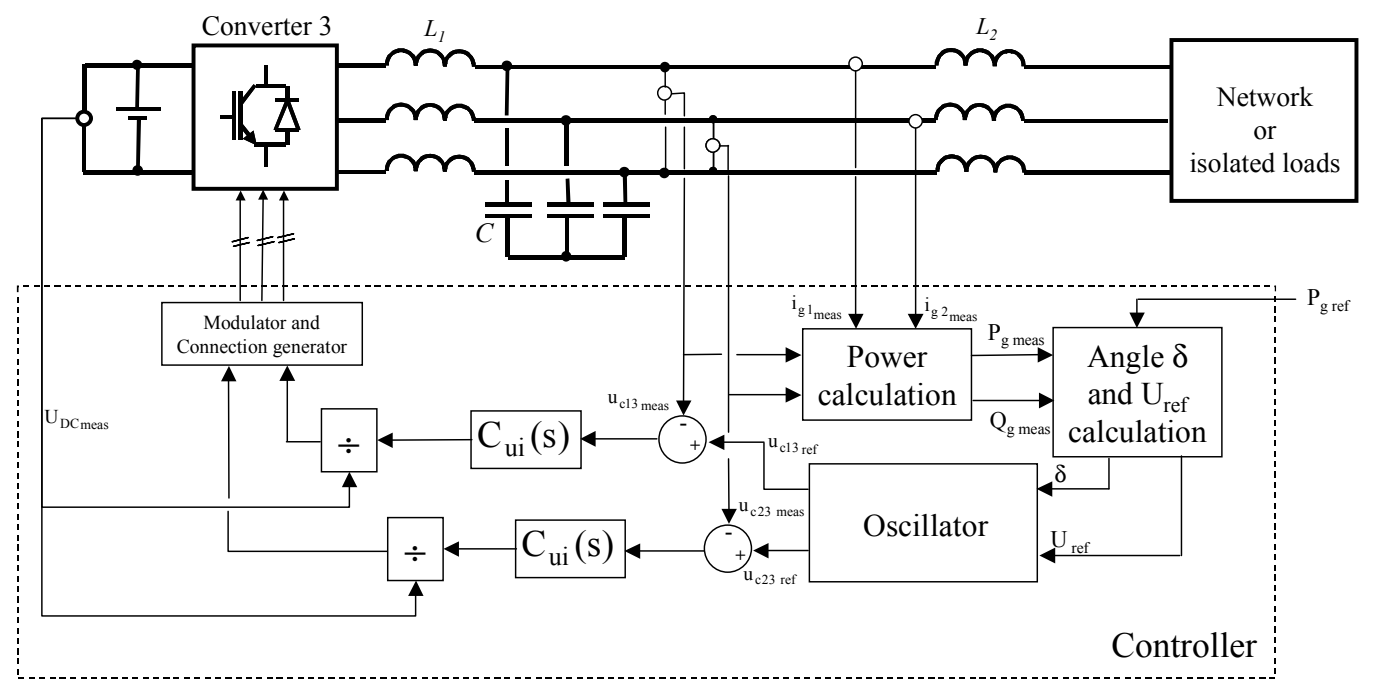

Fig. 2. Control scheme of converter 3. 


$$
P_{g}=\frac{3 V_{c} V_{g}}{L_{2} \omega_{0}} \sin \delta
$$

$\mathrm{V}_{\mathrm{c}}$ and $\mathrm{V}_{\mathrm{g}}$ are respectively capacitor and grid phase - to ground rms voltages. $\omega_{0}$ is the pulsation associated with $\mathrm{f}_{0}$.

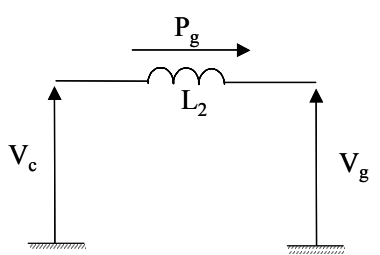

Fig. 3. Active power generated onto the network.

For small values of $\delta$, we can approximate the previous equation by :

$$
P_{g} \approx A \delta \text { where } A \approx \frac{3 V_{c}^{2}}{L_{2} \omega_{0}}
$$

$\delta$ is determined with the help of a frequency droop as shown in Fig. 4. The equation of this droop is :

$$
f=k\left(P_{\text {gref }}-P_{\text {gmeas }}\right)+f_{0} \text { where } k=\frac{\Delta f}{\Delta P_{g}}
$$

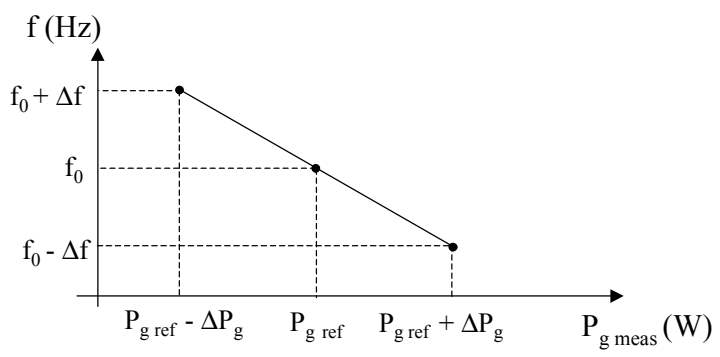

Fig. 4. Frequency droop.

The angle $\delta$ is related to (5) by the following relationship:

$$
\frac{d \delta}{d t}=\Delta \omega=2 \pi\left(f-f_{0}\right)=2 \pi k\left(P_{\text {gref }}-P_{\text {gmeas }}\right)
$$

Fig. 5 shows the $\delta$ angle determination deduced from (4) and (5) by neglecting the voltage control time response. An unity gain low pass filter, whose time constant is named $\tau$, is included to reduce the amplitude of an eventual fluctuating power due to unbalanced loads (moreover, a filter is necessary in case of single phase scheme). The low pass filter is placed after the comparator to avoid a zero in the closed loop control.

From Fig. 5, a second order active power transfer function can be deduced :

$$
\frac{P_{\text {gmeas }}}{P_{\text {gref }}}=\frac{1}{1+\frac{1}{2 \pi k A} s+\frac{\tau}{2 \pi k A} s^{2}}
$$

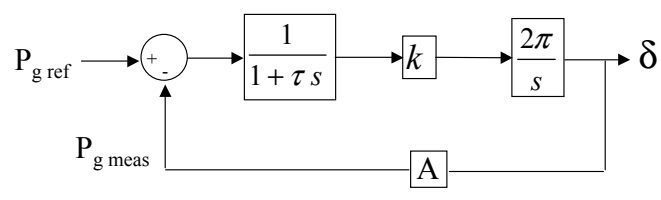

Fig. 5. Generating system delivered active power closed loop control.

(7) allows us to determine coefficient $\mathrm{k}$ (droop effect) and $\tau$ (damping effect).

\section{3) Active power set point determination}

We previously introduced the reference value of the active power feeding the network, $\mathrm{P}_{\text {gref. }}$. This value depends on the energetic state of the flywheel energy storage system i.e. its rotating speed. In fact, when the FESS speed $\mathrm{N}_{\mathrm{f}}\left(\Omega_{\mathrm{f}}\right.$ in rad.s $\left.\mathrm{s}^{-1}\right)$ is over $3500 \mathrm{rpm}$, we consider that the energy stored is sufficient to allow the generating system to deliver its rated power $P_{n}$. But, if the wind is too slow, i.e. the wind power is too small, then the flywheel will discharge and its speed will decrease. Below $3500 \mathrm{rpm}$, we consider that the FESS energy state is relatively low. This leads to a lower $\mathrm{P}_{\text {gref }}$ value. If speed reaches $3000 \mathrm{rpm}$, the FESS is no more charged and $\mathrm{P}_{\text {gref }}$ becomes null allowing, if possible, the flywheel speed to grow. This procedure is summarized in Fig. 6.

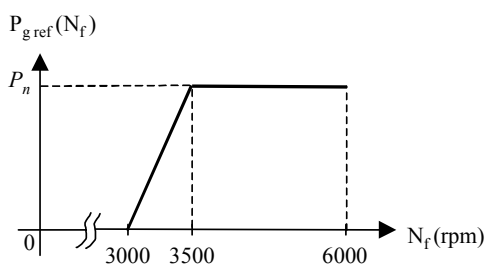

Fig. 6. $\mathrm{P}_{\text {gref }}$ determination.

It may be noticed that the control of $\mathrm{P}_{\mathrm{g}}$ is only possible in case of power grid feeding. If the generating system is connected to isolated loads, delivered power is fixed by them.

Besides, we have to manage active powers supplied by both components of the generating system i.e the wind generator power $\mathrm{P}_{\text {wgrefmax }}$ relies as well on the FESS rotating speed. Between $3000 \mathrm{rpm}$ and $5500 \mathrm{rpm}$, $P_{\text {wgrefmax }}$ is fixed to $P_{n}$. Above $5500 \mathrm{rpm}$, it is considered that the FESS is fully charged and therefore $\mathrm{P}_{\text {wgrefmax }}$ tends to decrease. As the speed reaches $6000 \mathrm{rpm}$, wind power generation is stopped in order to discharge the FESS. These considerations are summarized in Fig. 7. $\mathrm{P}_{\text {fref, }}$, the FESS reference active power, is then deduced according to Fig. 8 by taking into account $P_{\text {wg meas }}, P_{g \text { meas }}$ and an active power $\Delta \mathrm{P}_{\mathrm{DC}}$ allowing to control the DC link voltage.

The strategy, presented previously, may be improved in the future as it would be preferable to generate the maximum power onto the network even if the storage system is fully charged. However this very simple strategy is interesting when feeding isolated loads in case of islanding. In this context, Fig. 8 which depicts the power reference of the storage system determination, represents the precursory of a generating system supervisor. 


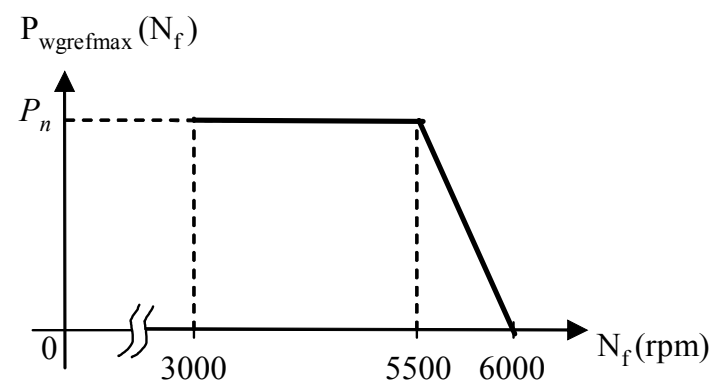

Fig. 7. $\mathrm{P}_{\text {wgrefmax }}$ determination.

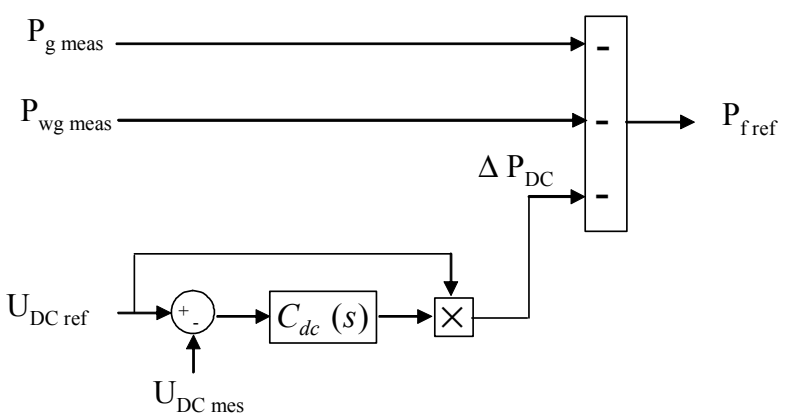

Fig. 8. Power reference of the storage system determination.

Fig. 9 depicts the whole system control which includes the LC filter capacitor voltage loop and active power ones described above. In this figure, $\mathrm{i}_{\mathrm{SG}}$ and $\mathrm{i}_{\mathrm{M}}$ refer respectively to PMSG and induction machine currents. $\Omega_{\mathrm{t}}$ represents the wind turbine rotation speed.

\section{Wind Farm simulation}

\section{A. Network connection}

We simulate the network represented in Fig. 10 in which we consider three identical generating systems (GS1, GS2, GS3), like the one presented in the previous section. These wind turbine based generators are submitted to three different wind speeds, $\mathrm{v}_{\mathrm{w} 1}, \mathrm{v}_{\mathrm{w} 2}, \mathrm{v}_{\mathrm{w} 3}$ whose values were measured in the north of France. These wind speed evolutions are shown in Fig. 12. They have an average value of respectively $6 \mathrm{~m} \cdot \mathrm{s}^{-1}, 10 \mathrm{~m} \cdot \mathrm{s}^{-1}$ and $12 \mathrm{~m} \cdot \mathrm{s}^{-1}$. The three generating systems are linked to the same bus bar named BB1, considering connection line impedances $Z 1$, $\mathrm{Z} 2$ and $\mathrm{Z3}$, and at which three loads are connected. Two other bus bar are present : BB2 is connected to a power grid and, at BB3, three other fixed loads are connected. The six balanced loads, load 1 to load 6 , of inductive nature, have same active and reactive powers : with $\mathrm{P}=$ $200 \mathrm{~kW}$ and $\mathrm{Q}=50 \mathrm{kVAR}$. The whole network has been simulated with Matlab - Simulink ${ }^{\mathrm{TM}}$ software with the help of the Sim Power System toolbox. The aim of simulations is to introduce severe events on the network in order to point out the behaviour of wind generators associated with flywheel energy storage systems. Therefore we have chosen to simulate a grid disconnection at time $150 \mathrm{~s}$ with a total load which varies between [400 kW; $100 \mathrm{kVAR}]$ and [1200 kW; 300 kVAR] as shown in Fig. 11, i.e an islanding mode where generating systems must supply the power demand of each load with rated voltage and frequency. The rated active power of each generating system is $600 \mathrm{~kW}$.

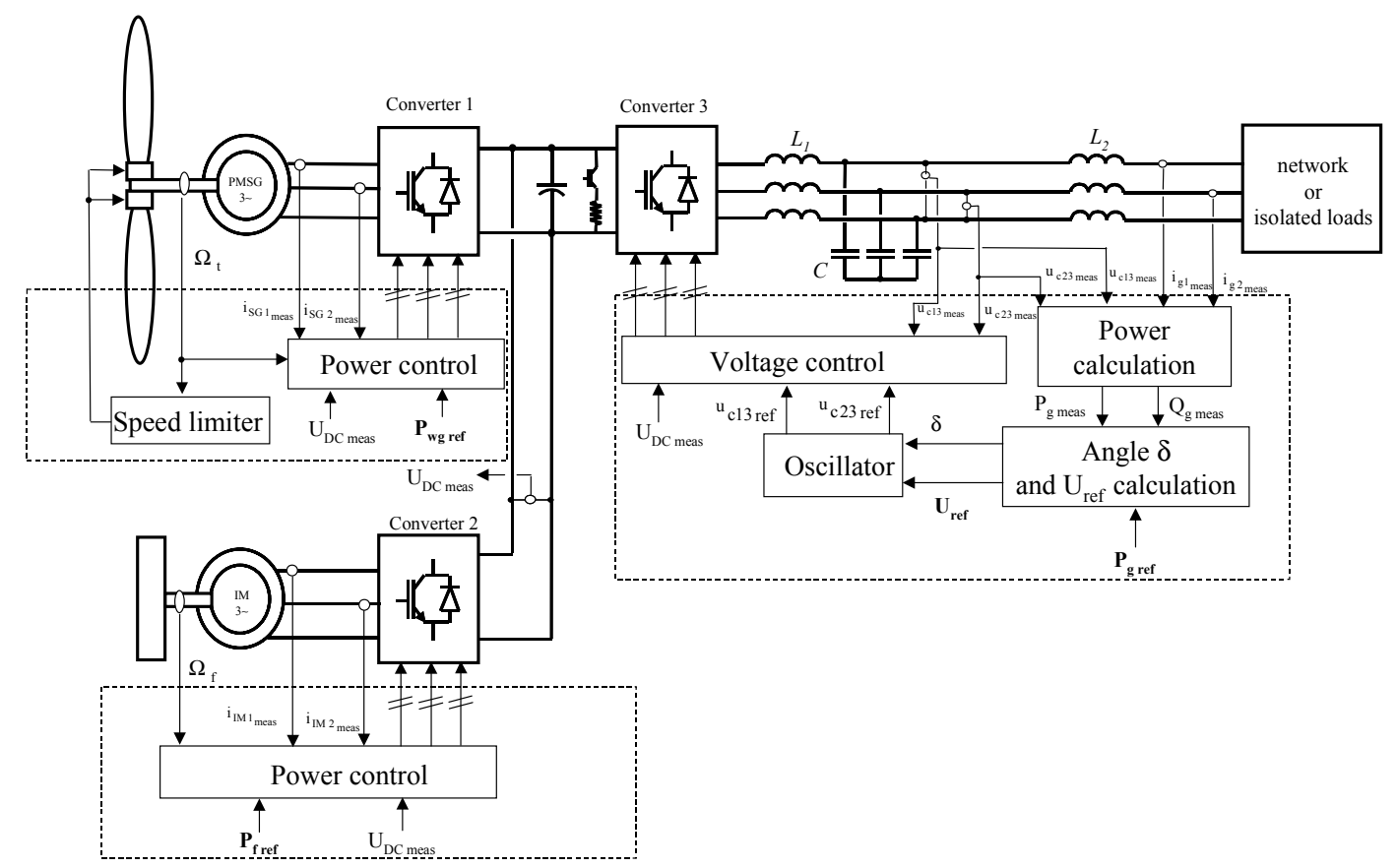

Fig. 9. Generating System control scheme. 


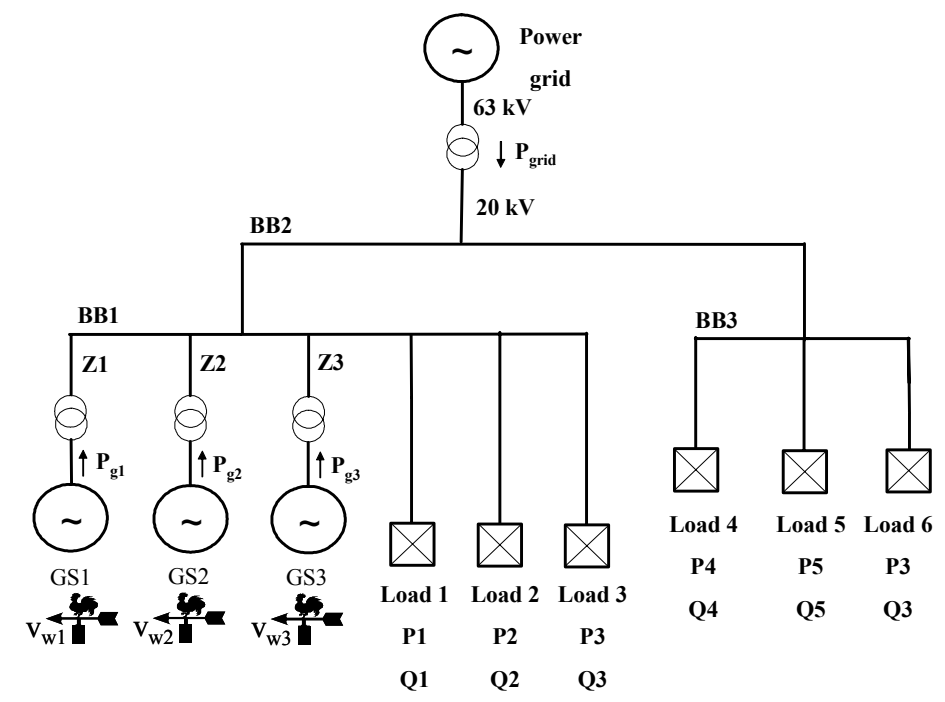

Fig. 10. Simulated network configuration.

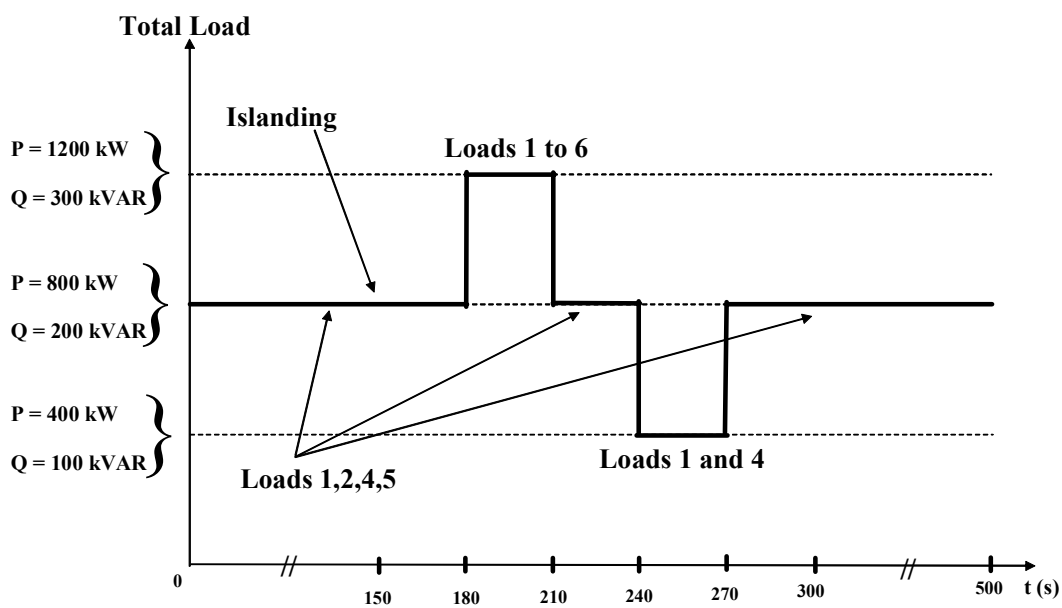

Fig. 11. Load curve.

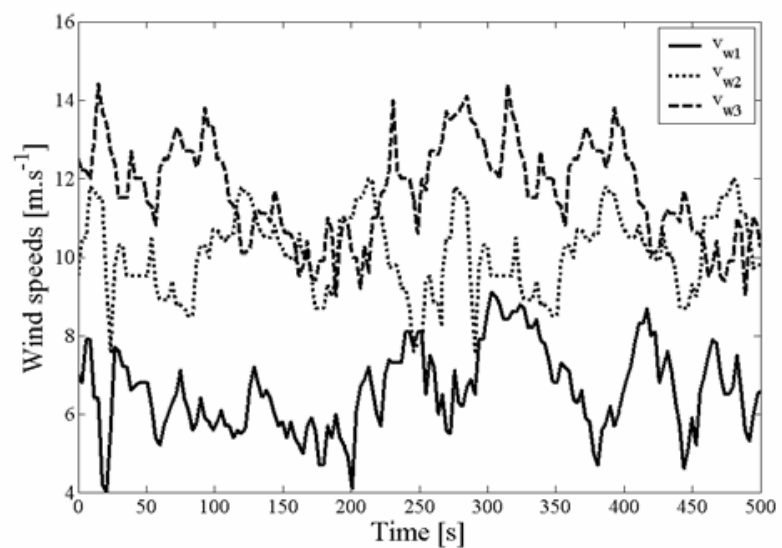

Fig. 12. Wind speed evolutions.

\section{B. Simulation}

1) Constant wind speed

A first simulation has been made by considering constant wind speed (respectively the average value of the wind speed shown in Fig. 12). The simulation allows to show the behaviour of the system in case of an islanding followed by significative load variations.

Simulation results are presented in Fig. 13 to Fig. 18. Fig.13 shows the three wind generator active powers $\mathrm{P}_{\mathrm{wg} 1}, \mathrm{P}_{\mathrm{wg} 2}$ and $\mathrm{P}_{\mathrm{wg} 3}$, i. e. measured at the exit of converter 1 of each generating system. Fig. 14 shows the active powers $\mathrm{P}_{\mathrm{g} 1}, \mathrm{P}_{\mathrm{g} 2}$ and $\mathrm{P}_{\mathrm{g} 3}$ generated by the three generating systems (at the beginning of the simulation $\mathrm{P}_{\mathrm{g} 1}=\mathrm{P}_{\mathrm{g} 2}=$ $\mathrm{P}_{\mathrm{g} 3}$ ) and $\mathrm{P}_{\text {grid }}$, the active power supplied by the grid. Fig. 15 shows the corresponding reactive powers. Fig.16 shows the FESS flywheel rotating speeds. Fig. 17 represents the three bus bar rms voltages $\mathrm{U}_{\mathrm{BB} 1}, \mathrm{U}_{\mathrm{BB} 2}$ and $\mathrm{U}_{\mathrm{BB} 3}$. Fig. 18 represents the generating system reference frequencies $f_{\mathrm{g} 1}, \mathrm{f}_{\mathrm{g} 2}, \mathrm{f}_{\mathrm{g} 3}$ and $\mathrm{f}_{\text {grid }}$, the grid frequency.

\section{a) Grid connected}

From $\mathrm{t}=0 \mathrm{~s}$ to $\mathrm{t}=150 \mathrm{~s}$, the power grid, the generating systems and a part of the loads are connected. The generating systems supply the total load active power as shown in Fig. 14. The bus bar voltages $\mathrm{U}_{\mathrm{BB} 1}, \mathrm{U}_{\mathrm{BB} 2}$ and $\mathrm{U}_{\mathrm{BB} 3}$ are close to $20 \mathrm{kV}$ as shown in Fig. 17. The generating system reference frequencies vary, according to the active power variations that they inject, around 
$50 \mathrm{~Hz}$ (Fig. 18). As shown in Fig. 13, when the wind speed is high enough, the wind generators supply the rated power, else they supply the maximum power which may be extracted from the wind. Fig. 16 shows that the flywheel rotating speed of GS1 and GS2 tend to decrease because the FESS discharges. This is due to the fact that $\mathrm{V}_{\mathrm{w} 1}$ and $\mathrm{V}_{\mathrm{w} 2}$ have small values and that we try to generate the rated power into the grid. To avoid the limitation of the FESS, the power set point is changed, according to the supervisory strategy, when the flywheel rotating speed becomes lower than $3500 \mathrm{rpm}$. Therefore, when the flywheel rotating speed $\mathrm{N}_{\mathrm{f} 1}$ of GS1 and $\mathrm{N}_{\mathrm{f} 2}$ of GS2 become inferior to that threshold (at a time close to $30 \mathrm{~s}$ for $\mathrm{N}_{\mathrm{f} 1}$ and to $100 \mathrm{~s}$ for $\mathrm{N}_{\mathrm{f} 2}$ ), the power generation $\mathrm{P}_{\mathrm{g} 1}, \mathrm{P}_{\mathrm{g} 2}$ and $\mathrm{P}_{\text {grid }}$ decrease as shown in Fig. 14.

\section{b) Grid disconnected: Islanding Mode}

$\mathrm{A} \mathrm{t}=150 \mathrm{~s}$ the grid is disconnected. Only the generating systems supply the loads. Between $t=180 \mathrm{~s}$ and $t=270 \mathrm{~s}$, the load varies. The bus bar voltages $\mathrm{U}_{\mathrm{BB} 1}, \mathrm{U}_{\mathrm{BB} 2}$ and $\mathrm{U}_{\mathrm{BB} 3}$ remain close to $20 \mathrm{kV}$ as shown in Fig. 17. The generating system reference frequencies remain close to $50 \mathrm{~Hz}$ (Fig. 18). The generating systems generate the active and reactive powers consumed by the loads and react correctly to sudden load variations.

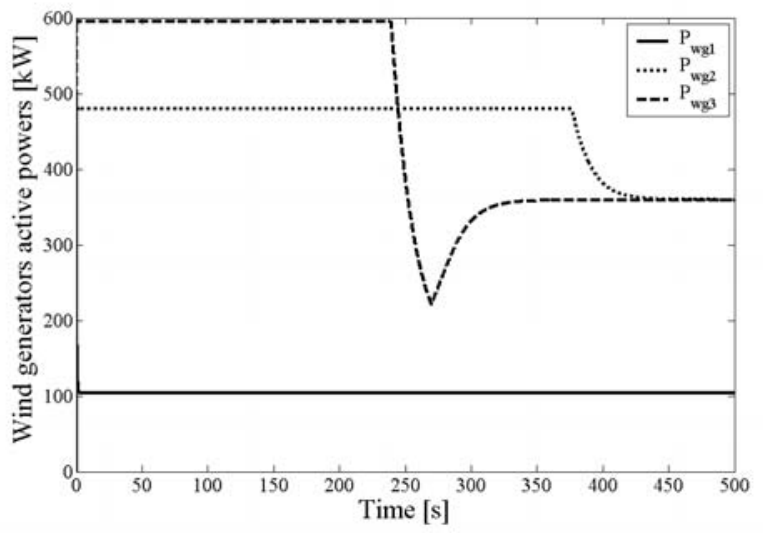

Fig. 13. Wind generator active powers.

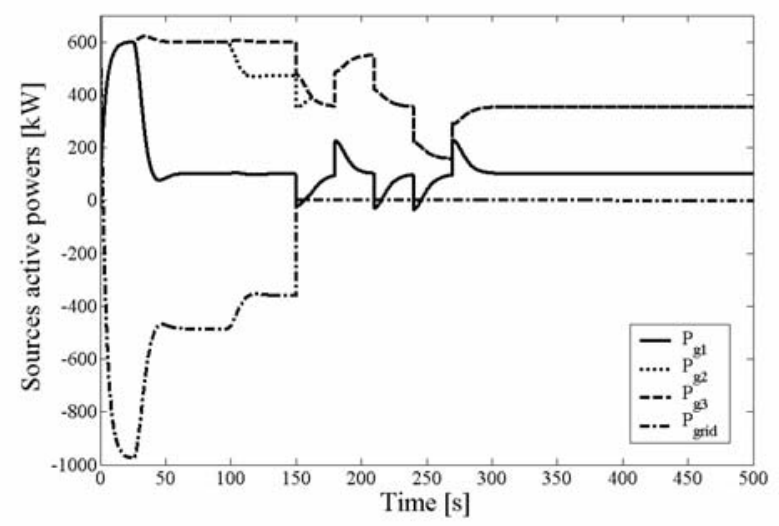

Fig. 14. GS and grid active powers.

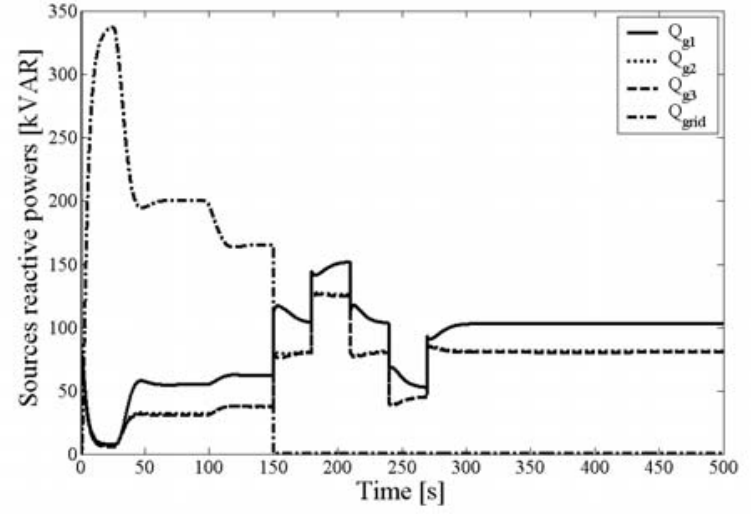

Fig. 15. GS and grid reactive powers.

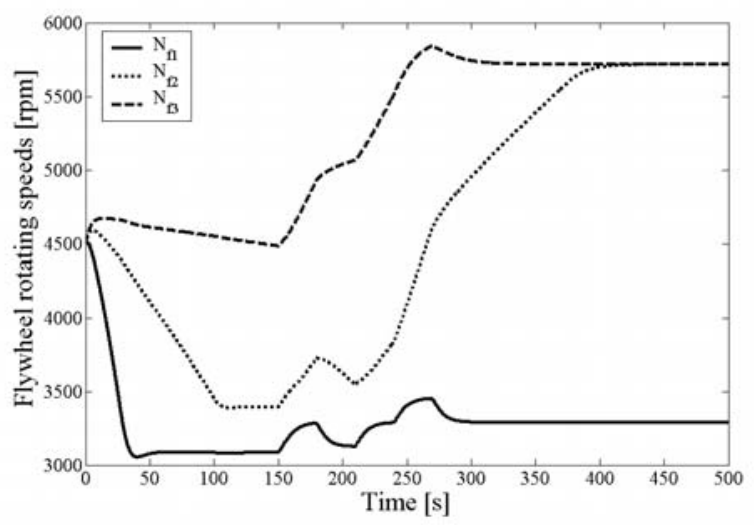

Fig. 16. Flywheel rotating speeds.

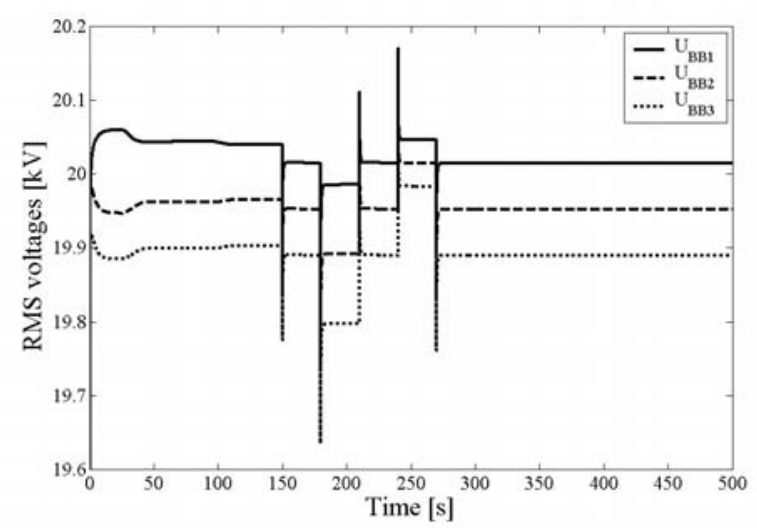

Fig. 17. Bus bar voltages.

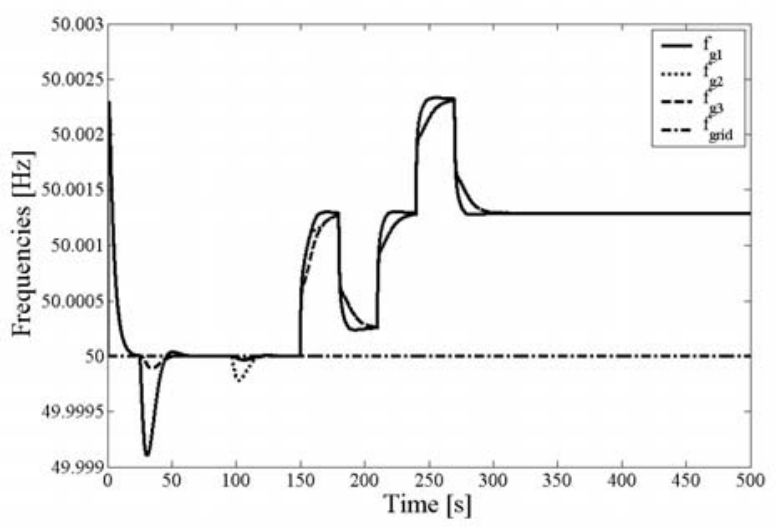

Fig. 18. Generating system reference and grid frequencies. 


\section{2) Variable wind speed}

In simulation results presented in Figs. 19 to 24, the same scenario (islanding and load variations) has been considered like in previous simulation (Figs. 13 to 18) but the variable wind speed shown in Fig. 12 are considered. The same comments as in previous simulation can be made in spite of an increase of the fluctuation of the different powers. The comparison of Figs. 19 and 20 points out that the storage system contributes well to power smoothing.

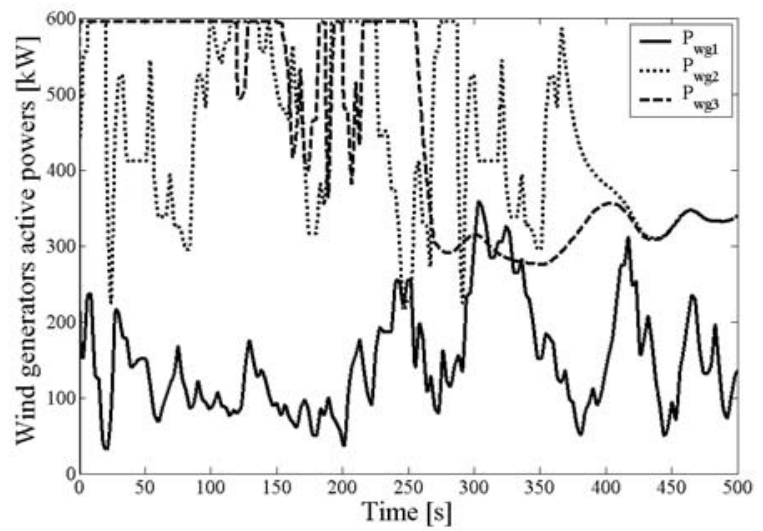

Fig. 19. Wind generator active power.

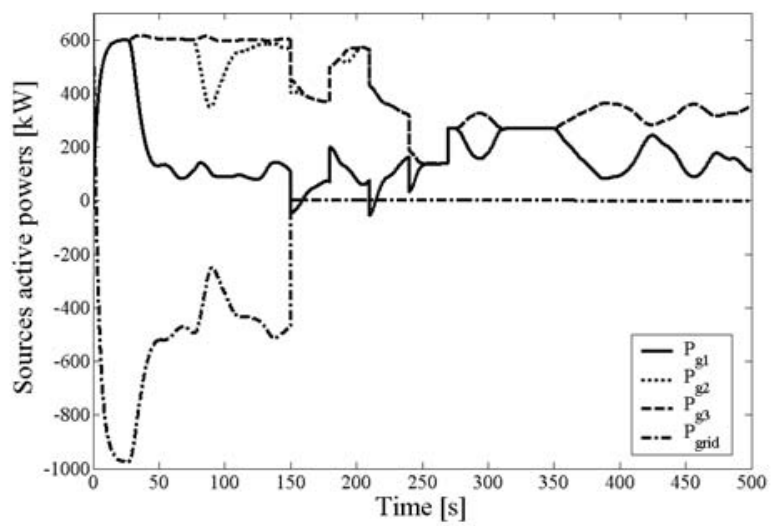

Fig. 20. GS and grid active powers.

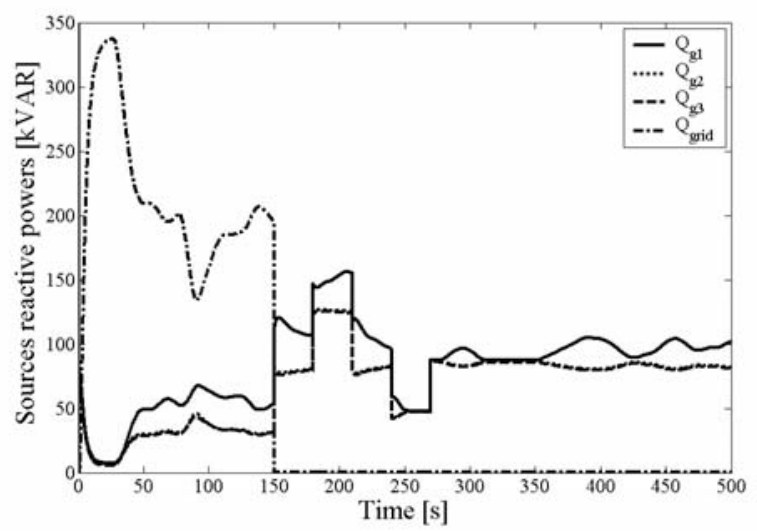

Fig. 21. GS and grid reactive powers.

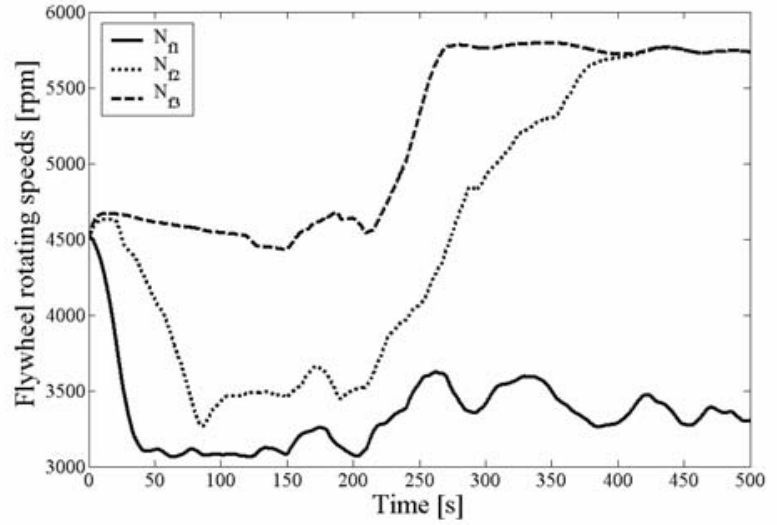

Fig. 22. Flywheel rotating speeds.

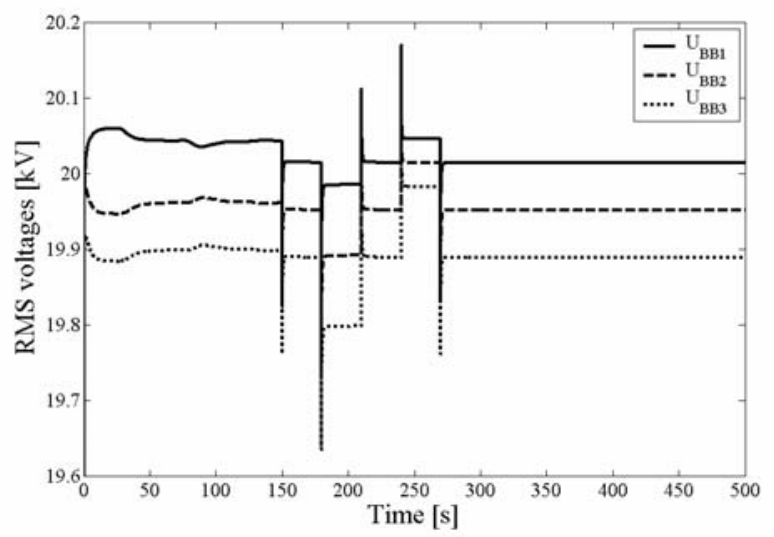

Fig. 23. Bus bar voltages.

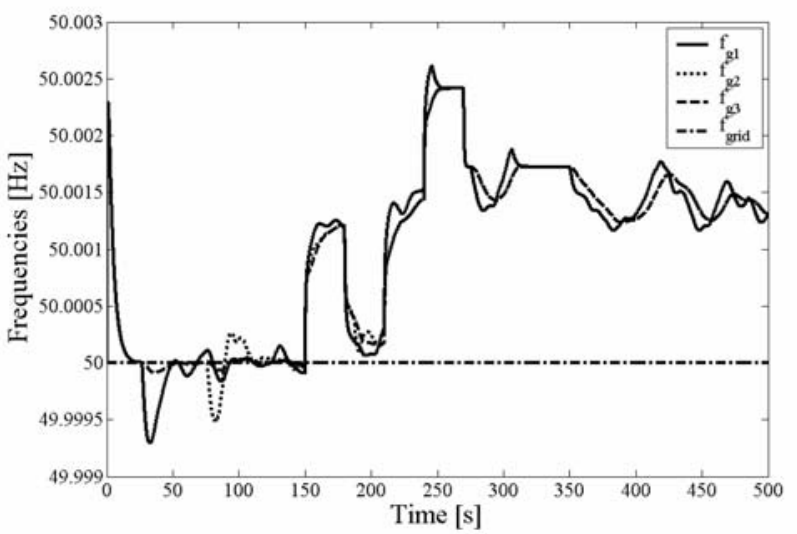

Fig. 24. Generating system reference and grid frequencies.

\section{Conclusion}

In this paper, a wind farm, which associates three generating systems, each composed of a variable speed wind turbine and a flywheel energy storage system, connected to a power grid has been presented. It has been shown that the power generated by the wind farm can be controlled by fixing the generating system power set points when it is connected to the grid and that it can supply the loads in islanding mode. In this last operation mode, the bus bar voltages and the frequency are close, respectively, to $20 \mathrm{kV}$ and $50 \mathrm{~Hz}$ in spite of load variations. The wind farm limitation is, of course, the wind speed level but it can play a significant role during 
disturbances on the power grid (power generation losses, islanding mode...). Simulation results, with this generating system, are encouraging. A $3 \mathrm{~kW}$ test bench is currently being developed in our laboratory to validate the proposed generating system [12].

\section{References}

[1] N.Jenkins, R.Allan, P.Crossley, D.Kirschen and G.Strbac, "Embedded generation", The Institution of Electrical Engineers (IEE), London, 2000, ISBN 0-85296-774-8.

[2] M.Crappe, "Commande et régulation des réseaux électriques", Hermés Science, Paris, 2003, ISBN 2-74620606-4.

[3] J.-L.Fraisse, "Le raccordement de la production décentralisée en HTA et BT", Revue REE, n7, July 2002

[4] W.Leonhard, "Feeding the grid from regenerative sources, the way to a sustainable energy supply?", EPE Journal, vol. 13, n³, pp. 38-42, August 2002.

[5] L.Leclercq, A.Ansel, B.Robyns, "Autonomous high power variable speed wind generator system", EPE 2003, Toulouse, France, September 2003.

[6] R.Hebner, J.Beno, A.Walls, "Flywheel Batteries Come Around Again", IEEE SPECTRUM, pp. 46-51, April 2002

[7] "Energy Storage. A key technology for decentralized power, power quality and clean transport", European Communities, 2001, ISBN 92-894-1561-4.

[8] A.Davigny, L.Leclercq, A.Ansel, B.Robyns, "Wind and storage system based dispersed generation contribution to a power grid ancillary services and network reliability", 2nd International conference on Securing Critical Infrastructures, CRIS 2004, October 25-27, 2004, Grenoble, France.

[9] U.Borup, F.Blaabjerg, P.N.Enjeti, "Sharing of Nonlinear Load in Parallel-Connected Three- Phase Converters", IEEE Transactions on Industry Applications, Vol. 37, $\mathrm{n}^{\circ}$, pp. 1817-1823, November/December 2001.

[10]E.A.A.Coelho, P.C.Cortizo, P.F.D.Garcia, "Small-Signal Stability for Parallel-Connected Inverters in Stand Alone AC Supply Systems", IEEE Transactions on Industrial Applications, Vol. 38, n², pp. 533-542, March/April 2002.

[11]A.Tuladhar, H.Jin, T.Unger, K.Mauch, "Control of Parallel Inverters in Distributed AC Power Systems with Consideration of Line Impedance Effect", IEEE Transactions on Industrial Applications, Vol. 36, $\mathrm{n}^{\circ} 1$, pp. 131-137, January/February 2000.

[12] C.Saudemont, G.Cimuca, B.Robyns, M.Radulescu , "Grid connected or stand-alone real-time variable speed wind generator emulator associated to a flywheel energy storage system", Proceedings of the 11th Conference on Power Electronics and Applications (EPE 2005), September 11 14, 2005, Dresden, Germany. 